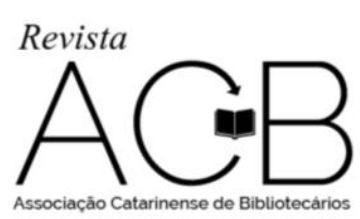

\title{
A BIBLIOCLASTIA NO INÍCIO DO SÉCULO XXI: DUAS FACES DE UMA TRAGÉDIA
}

\section{Josiel Machado Santos ${ }^{1}$}

RESUMO: Como resultado de dois acontecimentos que marcaram o cenário internacional no início da última década - um tsunami e uma guerra -, o artigo aborda a situação em relação às perdas humanas, físicas e principalmente danos causados em vários países da Ásia pelo "Tsunami" e pela guerra no Iraque, às suas bibliotecas e ao sistema escolar. As consequências desses dois desastres impactaram negativamente no mundo da cultura, seja pelo atraso ou pelas grandes perdas que tem significado por um lado, um desastre natural, e, por outro, o terrível flagelo da guerra. A grande diferença é que o primeiro foi causado pela natureza, e o segundo, por uma ação humana com a intenção de provocar um "memoricídio". Ambos, no entanto, são exemplos do que os gregos chamavam de "biblioclastia", isto é, a destruição de bibliotecas.

Palavras-chave: Bibliotecas. Biblioclastia. Desastres naturais. Destruição de bibliotecas. Memória.

\section{INTRODUÇÃO}

Ao longo da história muitos desastres têm ocorrido, sejam naturais, induzidos ou permitidos por pela ação humana que objetivam acabar com os registros do passado: terremotos, tsunamis, incêndios, inundações, intervenções, revoluções e guerras, que tem ocasionado inúmeros estragos e flagelos à humanidade.

Como resultado, além dos males e prejuízos causados à população (mortos, desaparecidos e feridos), o patrimônio cultural sofre enormes danos que têm deixado sem registros escritos, sem recursos de imagens e sem outros objetos considerados como fonte de informação e conhecimento dos diversos povos, tais como arquivos, bibliotecas, museus ou até mesmo cidades e jardins antigos estes últimos considerados museus vivos. Muitos desses infortúnios nos remontam a antigas, modernas e contemporâneas civilizações que têm sido testemunhas dessas grandezas culturais.

Neste raciocínio, as bibliotecas, consideradas como os principais repositórios do conhecimento humano, tem sido frequentemente vítimas desses eventos, uma vez que nelas se

\footnotetext{
1 Bacharel em Biblioteconomia pelo Centro Universitário de Formiga (UNIFOR-MG) - 2007. Especialista em Biblioteconomia pelas Faculdades Integradas de Jacarepaguá (FIJ) - 2013. Especialista em Gestão de Bibliotecas Públicas pela AVM Faculdade Integrada (IAVM) - 2014. Atualmente, Bibliotecário-Documentalista da Universidade Federal de Minas Gerais (UFMG) - Campus Montes Claros. E-mail: lordjosiel@ yahoo.com.br
} 


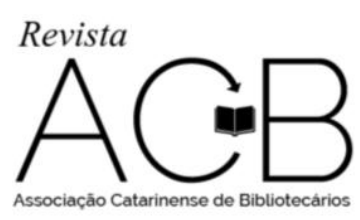

localizam as fontes de informações que foram criadas, mas que também ali se guardam os tesouros de gerações. É famosa a de Alexandria porque, além de seu nome e sua importante coleção, de acordo com determinadas fontes, sucumbiu a um incêndio provocado inicialmente no porto e que foi estendido ao museu que a abrigava; outros afirmam que depois de oito séculos de existência, com o florescimento do Império Romano, a biblioteca desapareceu quando seus acervos foram utilizados como combustíveis para os banhos públicos. Também não faltam versões que afirmam que seu desaparecimento se deve como consequência das permanentes e constantes revoltas ocasionadas entre as diferentes nacionalidades da época que ocupavam a cena política (ESCOLAR SOBRINO, 1990).

Assim, a Biblioteca de Alexandria geralmente tem é tornado como um ponto de referência para os estudiosos, para exaltar os sentimentos produzidos pelo desaparecimento dos edifícios e dos espaços que guardam as bibliotecas. Historiadores narram e descrevem com preocupação a biblioclastia no Oceano Índico, por razões como o tsunami, e outra pior, a destruição e saques de museus, monumentos, coleções de livros e documentos de grande valor, devido à intervenção e guerra dos Estados Unidos contra o Iraque em 2003.

\section{O TSUNAMI}

O tsunami, por vezes também chamado de maremoto, é uma série de ondas de água causada pelo deslocamento de um grande volume de um corpo de água, como um oceano ou um grande lago (HOUAISS; VILLAR, 2009). Ferreira (2010) diz ainda que o tsunami pode atingir mais de $700 \mathrm{~km} / \mathrm{h}$ e provocar enorme devastações em áreas costeiras. Esse evento tem uma ocorrência frequente, em especial, no Oceano Pacífico: aproximadamente 195 eventos desse tipo já foram registrados.

Sismos, erupções vulcânicas e outras explosões submarinas (detonações de artefatos nucleares no mar), deslizamentos de terra e outros movimentos de massa, impactos, e outros distúrbios acima ou abaixo da água têm o potencial para gerar um tsunami. O historiador grego Tucídides (2013) foi o primeiro a relacionar um tsunami a sismos submarinos, mas a compreensão da natureza do tsunami permaneceu incipiente até o século XX e ainda é objeto de pesquisa. Muitos textos antigos geológicos, geográficos e oceanográficos referem-se a tsunamis como ondas sísmicas do mar. 


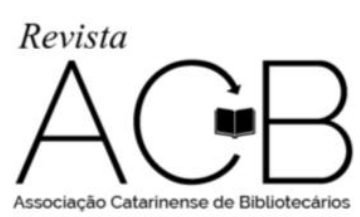

Algumas condições meteorológicas, tais como depressões profundas que provocam ciclones tropicais, podem gerar uma tempestade chamada meteotsunami (tsunami meteorológico), o que pode elevar as marés a vários metros acima do nível normal. O deslocamento vem da baixa pressão atmosférica no centro da depressão. Essas tempestades atingem a costa, o que pode assemelhar-se (embora não o são) a tsunamis, inundando vastas áreas de terra.

Passados mais de dez do tsunami que atingiu vários países da Ásia, é particularmente importante refletir sobre os efeitos que provocados por um desastre natural como esse. Infelizmente não é pior do que a perda de mais de 230 mil vidas e centenas de milhares de pessoas afetadas em suas propriedades e bens materiais como motivos de um desastre natural ou uma guerra. Além disso, a destruição do patrimônio cultural contribui para somar-se às maiores tragédias que a humanidade possa atravessar.

Essa é a principal preocupação levantada em seu artigo pelo Dr. Upali Amarasiri intitulado "Rising from the wreckage: development of tsunami-affected libraries in Sri Lanka":

Às 07h58, hora local, do dia 26 de dezembro de 2004, a crosta terrestre no fundo do mar ao largo da costa oeste de Sumatra foi deslocada violentamente, levantando o fundo do mar por cerca de 15 metros. O impulso sísmico, o maior do mundo em 40 anos, com mais de 9,0 graus na escala Richter, enviou ondas de choque através do Oceano Índico, causando ondas a uma velocidade de 700 quilômetros por hora em todas as direções. A grande cortina de água rugiu através do oceano como um proverbial dragão marinho ou tão rápido quanto um avião a jato. Levou apenas vinte minutos para chocar-se com a província de Achém, na Indonésia, oitenta minutos para chegar à Tailândia e noventa minutos para chegar ao Sri Lanka e Índia. Em poucas horas, causou uma destruição colossal em uma série de países da Ásia, nomeadamente, Indonésia, Sri Lanka, Índia, Tailândia, Malásia, Mianmar, Maldivas e Bangladesh. As ondas, em seguida, rumaram até a África Oriental, afetando Somália, Tanzânia e Quênia (2005, p. 307-308, tradução nossa).

A tragédia imensurável causada pelo tsunami revelou a triste realidade dos países pobres. Em outras palavras são esses os países mais atingidos pela natureza com tais fenômenos, já que eles não têm infraestrutura pouco preparada para se defender em tempo hábil contra os diferentes fenômenos. Neste caso as consequências imediatas foram as centenas de milhares de mortos, feridos e desaparecidos, e a dor causada às famílias e populações pelas enormes perdas materiais e culturais, que ainda estão sendo sentidas mais de uma década após o infortúnio.

As ajudas que receberam os países afetados serviram para enfrentar os efeitos mais urgentes da tragédia. Entretanto, a solidariedade de muitas nações e a obrigação das 


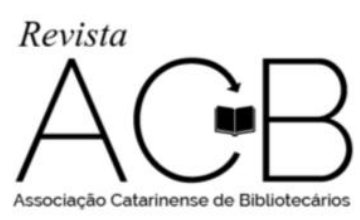

instituições financeiras internacionais para alocar fundos especiais para esses casos não foram suficientes para compensar as consequências físicas da situação.

Deve-se levar em conta que aldeias inteiras foram arrasadas, danificando a infraestrutura turística, habitação, agricultura, pesca, água e eletricidade, bem como o envolvimento direto em serviços de saúde e educação e grande parte do patrimônio cultural. Nos países afetados, que já foram consideradas de um alto nível de pobreza, a sua população mal vive com menos de um ou dois dólares por dia.

Nota-se nesse ponto uma das primeiras diferenças entre países pobres e ricos: enquanto no segundo reconstruções são realizadas em um curto espaço de tempo, nos primeiros, apesar da ajuda internacional, que será sempre baixa, pode mesmo se levar anos e nunca se restaurar ou consertar todas as partes em relação ao todo. Exemplo desse fato pode ser citado o caso do Haiti que, em 2010, um terremoto de magnitude 7,0 na escala Richter atingiu o país. Esse fato promoveu grande destruição na região da capital haitiana e, estima-se que metade das construções foram destruídas, 250 mil pessoas foram feridas, 1,5 milhão de habitantes ficaram desabrigados e o número de mortos ultrapassou 200 mil. Até hoje o país não teve sua infraestrutura mínima restabelecida, apesar de todos os pedidos de ajuda da Organização das Nações Unidas (ONU).

O impacto do tsunami no campo da cultura, especialmente nos bens patrimoniais, foram consideráveis. A Organização das Nações Unidas para a Educação, Ciência e Cultura (UNESCO), apresentou na época, um chamado urgente que, além da comunidade internacional expressar sua solidariedade para a reconstrução das áreas devastadas, ela também deveria ajudar a atender às necessidades das vítimas em matéria de educação, ciência, cultura e comunicação.

Esse apelo foi extremamente necessário devido à extensão dos danos na área de devastação, que foram calculados em cerca de 10 bilhões de dólares, impossíveis de pagar, porque cinco dos países mais afetados apresentavam, em 2004, uma dívida pública de aproximadamente 300 bilhões de dólares. A partir da devastação, os governos dos países mais afetados, apoiados por diversas organizações, pediram a credores e aos vários organismos, como o Banco Mundial, o Fundo Monetário Internacional e outros bancos privados, o perdão da dívida (RAMONET, 2005).

Dentro do relatório da UNESCO, observou-se que os danos também afetaram grandes zonas ecológicas e cinco sítios na lista de patrimônios da humanidade: a zona portuária, a 


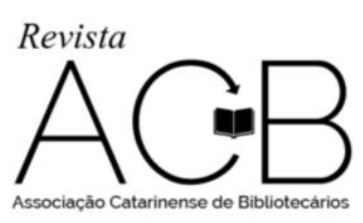

mais prejudicada, especialmente do Centro de Arqueologia Submarina, de onde se dirigiam as escavações de barcos holandeses afundados no porto; do centro histórico e muralhas de Galle, no Sri Lanka. Os parques nacionais de Ujung Kulon e o bosque tropical chuvoso de Sumatra, na Indonésia; a cidade de Georgetown em Penjan e Malaca, na Malásia. A devastação também causou enormes danos no Templo do Sol em Konarak, na Índia.

A questão que chama bastante atenção são os poucos registros e/ou estudos acerca das consequências trazidas pelos tsunamis em termos dos efeitos sobre a educação e perdas de bibliotecas e suas coleções. Até agora, são escassas as informações, porque, infelizmente, são os aspectos mais negligenciados em todos os países, quando surgem infortúnios como esse. Por isso, não há informações suficientes sobre o que aconteceu nessas áreas. Portanto, assume maior valor o levantamento do estudo que fez o diretor da Biblioteca Nacional do Sri Lanka, que proporciona dados altamente precisos das perdas, como o número de alunos, suas famílias, escolas, bibliotecas, livros, documentos, e até mesmo o desaparecimento de um grande número de professores, como causa do maremoto.

Em um outro cenário, esse de guerra, Amarasiri (2005) argumenta que, desde a catástrofe da Biblioteca de Alexandria até a intervenção pelos Estados Unidos e, posterior, guerra no Iraque, é a Biblioteca Nacional do Sri Lanka, que teve, nos últimos tempos, os piores danos a sua estrutura física e também ao seu acervo bibliográfico. Assim, relaciona o número de mortes no país, que ascenderam a 36 mil, com a população em idade escolar, uma vez que um terço das crianças foram mortas e havia mais mulheres do que os homens; também ficaram órfãos de pai e mãe cerca de 3.070 crianças e 1.070 para um dos pais.

Resultado do desastre na infraestrutura das áreas atingidas: mais de 500 escolas danificadas, cerca de 3.500 professores e 80 crianças desalojadas e 282 escolas usadas para acomodar todos os desabrigados. Além disso, quatro universidades, três institutos de tecnologia e dez institutos de formação profissional também sofreram graves danos as suas estruturas. Estima-se que cerca de 1,2 milhão de livros e outros materiais de leitura foram perdidos (todavia, não se pode dizer exatamente o exato número, uma vez que os registros e catálogos foram destruídos), bem como coleções de livros que iriam ser distribuídas gratuitamente por um programa do governo entre os estudantes do primeiro ao décimo ano, ao início do ano escolar. De 950 bibliotecas públicas, 62 foram afetadas e 28 completamente destruídas. 


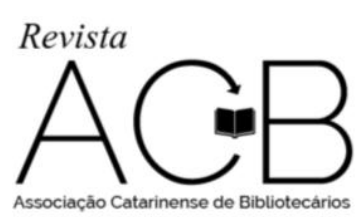

Outro grande impacto sobre outros tipos de bibliotecas foi que de 3.600 objetos de explorações arqueológicas que tinham sido salvos de um terremoto anterior, durante a década dos anos oitenta, $80 \%$ foi "devolvido" ao mar imediatamente depois do tsunami.

Nesta esteira ainda Amarasiri (2005) discorre sobre o que ele chama de "trauma dos bibliotecários" por causa das bibliotecas destruídas, coleções perdidas, os usuários que nunca mais voltarão e até mesmo as suas famílias e amigos que nunca estarão com eles. No período pós-tsunami, muitos deles perderam seus empregos, outros estão ocupados na reconstrução, outros a avaliar os danos às coleções ou que tenham sido utilizados em outros locais temporariamente. E há de se falar de todos os usuários afetados em todos os níveis de ensino escolar, assim como a falta de livros para continuar seus estudos.

Dentre as coisas mais lamentáveis no mundo da documentação, que desde dezembro de 2004 enfrentam os bibliotecários, estão precisamente as dificuldades de conservação e preservação de materiais, porque a água salgada do mar que entrou nos edifícios também continha lama, areia, diversos minerais e outras substâncias. De acordo com o laboratório do Arquivo Nacional do Sri Lanka, documentos danificados contêm mais ácido do que o normal, de modo que seu tratamento será mais caro em termos monetários e com maiores complicações para salvá-los.

Apesar de tudo isto, no período transcorrido desde então, percebe-se progressos significativos na reconstrução, graças aos esforços de diversas organizações nacionais e internacionais e comitês ad hoc que se esforçam para seguir em frente com os trabalhos no Sri Lanka: Biblioteca e Arquivo Nacional, a Associação Nacional de Ciência, ministérios, institutos de formação e a Federação Internacional de Associações e Instituições Bibliotecárias (IFLA).

O Comitê de Prevenção de Desastres para Bibliotecas, Serviços de Informação e Arquivos (SL DCM for LISA, sua sigla em inglês), traçou as seguintes metas: planejamento de equipamentos e construção de edifícios para as bibliotecas, educação e formação, manutenção, seleção de materiais, desenvolvimento de bibliotecas escolares e públicas, ligando todos os projetos entre si. 


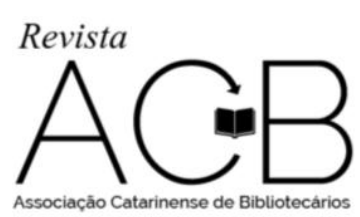

\section{A GUERRA CONTRA O IRAQUE}

Em 8 de abril de 2003, Bagdá, capital do Iraque, foi invadido pelos Estados Unidos e seus aliados, com o suposto fim de libertar o Iraque. As primeiras ações empreendidas foram a apropriação dos poços de petróleo, a procura ao ditador Saddam Hussein e temíveis ofensivas ao patrimônio cultural do país e de toda a humanidade.

No dia 11 de abril, foi provocado o primeiro incêndio, embora o maior e mais destrutivo fosse induzido pelas forças anglo-americanas no dia 14 e, após esse fato, começaram os terríveis saques que esvaziaram o Museu Nacional. Quase todos os 170 mil objetos museográficos haviam desaparecido, foram roubados ou destruídos, como a maior coleção de antiguidades do mundo da Suméria, Babilônia e Assíria, incluindo urnas, tabuletas cuneiformes de 5 mil anos de idade, consideradas as primeiras formas de linguagem escrita, as estátuas, entre outros. Entre as ruínas, por causa das chamas, foram localizados materiais inflamáveis que eram de uso das tropas de ocupação, porém utilizadas também por um grupo de iraquianos.

Em 13 de abril, a Biblioteca Nacional (Dar al-Katub wa al-Watha'iq), na qual se encontravam os arquivos nacionais e que guardava os livros mais antigos do mundo, assim como a Biblioteca Islâmica, onde havia milhares de exemplares do Alcorão, incluindo o mais antigo volume conhecido, arderam em chamas. James (20--) relata que

\footnotetext{
Enquanto isso, efetivos militares americanos protegiam zelosamente as instalações de petróleo e gás em Kirkuk, onde está quase um terço do petróleo do Iraque, e o Ministério do Petróleo, na capital. Outros ministérios, incluindo os do Comércio, Informação, Planejamento, Saúde e Educação, ficaram totalmente desprotegidos. Muitos observaram os paralelos com outros momentos sombrios da história, como o incêndio da Biblioteca de Alexandria, nas mãos dos romanos cerca de 1.600 anos atrás. (Tradução nossa).
}

Nada é comparável à tragédia patrimonial causada pelas guerras, porque são elas a destruição da cultura. A isso é se chama de "memoricídio", um neologismo utilizado por um dos especialistas mais experientes no estudo da biblioclastia: o venezuelano Fernando Báez. Esse autor visitou, inclusive, várias áreas destruídas pelos bombardeios em Bagdá, durante o mês de maio, trinta dias após a tragédia. Báez $(2004 ; 2006)$ afirma que “[...] quando se destrói a cultura, está se destruindo a memória. E esta se destrói para reconfigurar a identidade". Sobram testemunhos que corroboram que essa foi a ideia dos invasores, como uma maneira 


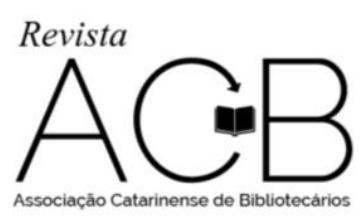

de fazer desaparecer uma cultura tão alheia a eles e também uma forma de acabar com o testemunho das origens da religião islâmica.

Importante relatório sobre a situação das bibliotecas universitárias, desde a invasão norte-americana, foi feito por Jeff Suprr, membro da Biblioteca da Faculdade de Belas Artes da Universidade de Harvard. No dito relatório, se expõe as advertências que o Conselho Internacional de Museus fez ao Departamento de Defesa dos Estados Unidos em relação a sua responsabilidade de proteger os bens culturais no âmbito da Convenção de Haia, datada de 1954 (ENGLISH, 2005). No entanto, o aviso foi ignorado, apesar da ênfase de que as perdas do patrimônio cultural seria uma perda para toda a humanidade.

Grande quantidade de bibliotecas, museus e sítios arqueológicos foram vandalizados, roubados e destruídos. Pelas investigações efetuadas tanto por Suprr como por Báez, confirmou-se que os responsáveis haviam sido membros baathistas (do partido Baath, fundado por Saddam Hussein) preocupados com documentos comprometedores (os iraquianos estavam contra o presidente recentemente deposto) e outros grupos, cujas motivações podem ter sido lucrar com a situação e receber parte desses recursos pelas mãos das tropas americanas.

A Biblioteca Nacional do Iraque e o Arquivo Nacional continham 12 milhões de documentos. Além de uma coleção substancial de livros, contavam também com a maior coleção de periódicos árabes do mundo. Continham ainda documentos desde o período turcootomano (1534- 1918) e da monarquia hachemita (1920-1958), bem como inúmeros documentos da recém-eliminada "república", fundada em 1958.

No entanto, houve muitos esforços de clérigos xiitas na tentativa de salvar parte da coleção de livros e documentos. Supõe-se que 35 a $40 \%$ desse material puderam ser transferidos para algumas mesquitas e também ao Escritório de Turismo. No entanto, esses locais foram inundados por saqueadores, o que levou esses documentos a sofrerem uma maior deterioração; além de que, na tentativa de protegê-los, muitos foram colocados em câmaras frigoríficas, aumentando os danos. Desse percentual, havia muitas pessoas que viram o que estava acontecendo, procurando preservar o que podiam, embora muitos materiais obtidos por saqueadores puderam ser vistos à venda em mercados de rua nos meses seguintes.

Após três meses da ocupação, a UNESCO dirigiu suas operações principalmente a avaliar os danos no Museu, deixando para depois o ocorrido na Biblioteca Nacional. Yriart (2008) diz que dos tesouros bibliográficos árabes, como originais de Averróis e Omar Kayam 


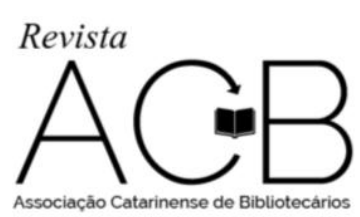

e traduções de Aristóteles, foram reduzidos a uma espessa camada de papel, papiro e pergaminho.

Quanto à semi-privada Biblioteca al Awqaf, fundada em 1920, durante os dias 13 e 14 de abril, de acordo com testemunhas, incendiários a destruíram completamente. Dos 45 mil livros, incluindo manuscritos otomanos e uma coleção de livros de medicina, não resistiram às chamas; tão pouco a equipe de segurança da biblioteca, fez algo para apagar o incêndio. Os funcionários puderam tão somente salvar 5.250 coleções das mais de 7 mil, incluindo uma coleção do Alcorão.

Outros 17.454 manuscritos que haviam sido enviados para a mesquita al Khadimiya e que estavam sob a custódia dos invasores, teve a sua guarda assassinada, deixando desprotegido a mesquita, que também foi saqueada e queimada. De acordo com o relatório de um estudante, quem ateou o fogo, foram quinze homens que aparentemente falavam o dialeto do Kuwait e estavam em tanques americanos, incentivando a revolta popular (YRIART, 2008).

O jornalista britânico especializado em Oriente Médio, Robert Fisk (2003), que testemunhou o saque e incêndio da Biblioteca, conta que tentou prevenir as forças de ocupação sobre o que estava ocorrendo, mas sua reclamação não foi levada em consideração. Em 13 de abril, enquanto ocorria o incêndio na Biblioteca Corânica, Fisk narra que

[...] chamas de 30 metros de altura fluía através de suas janelas. Corri para a sede da autoridade do poder de ocupação, o Escritório de Assuntos Civis dos fuzileiros navais norte-americanos... mostrei-lhes o ponto exato no mapa em inglês e em árabe ... Eu disse que a fumaça podia ser vista a partir de três milhas de distância e que levaria apenas cinco minutos de carro até lá. Meia hora mais tarde não tinha chegado qualquer americano no local, e as chamas atingiram os 50 metros. (Tradução nossa).

A Biblioteca "Casa da Sabedoria" nomeada assim em honra da dinastia abássida, criada em 838 e que havia sido destruída em 1258 pelos mongóis, havia sido reaberta a menos de dez anos atrás, em 1995, em um dos poucos edifícios sobreviventes do século XIII. Ali se guardava uma pequena coleção de cópias de manuscritos, incluindo um Alcorão do século IX. A instituição possuía cerca de 5.500 volumes relativos à comunidade judaica de Bagdá, registros otomanos e documentos judiciais. Os originais foram mantidos na Biblioteca Nacional e, portanto, foi uma dupla perda. English (2005) diz que “[...] os incendiários foram instigados e [...] os livros foram vistos a venda nas ruas de Bagdá." 


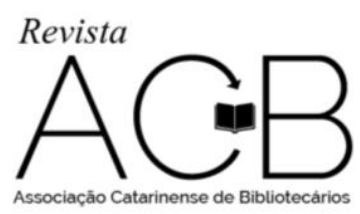

A Academia de Ciências continha livros estrangeiros, manuscritos e teses não publicadas, alojadas em um laboratório de internet e preservação digital. "Os trabalhadores alegam que, pouco depois da invasão, um tanque americano se chocou contra as portas do complexo, removendo a bandeira do Iraque [...]” (BÁEZ, 2006). Pouco depois, entraram os assaltantes levando computadores, móveis, carros e outros pertences dos trabalhadores.

A coleção inteira de 175 mil livros e manuscritos da Biblioteca da Faculdade de Belas Artes da Universidade de Bagdá, de acordo com Yriart (2008), foi reduzida a cinzas. A Biblioteca Central da Universidade de Basra, também perdeu 100\% de seu acervo em outro incêndio e a Biblioteca Central da Universidade de Mossul, com um acervo de aproximadamente 9 mil livros e outras coleções foi saqueado por "especialistas" nesse tipo de roubo. De acordo com as informações fornecidas por Báez (2003), durante a ocupação de outra cidade iraquiana, Nassíria, foram destruídos, em maio de 2004 (um ano após a ocupação), 40 mil manuscritos religiosos. Esse mesmo autor calcula que o total das perdas de livros iraquianos, periódicos e manuscritos, superam os 10 milhões de exemplares.

O relatório de Jeff Supr, anteriormente citado, destacou os principais problemas para a reconstrução de bibliotecas, pela deterioração da situação política e de segurança, além de escassos recursos financeiros. No entanto, a ajuda começou a fluir de instituições privadas e estrangeiras. Também participaram desse esforço a UNESCO e outras organizações das Nações Unidas, mas também limitadas pelas circunstâncias.

O Congresso Americano, paradoxalmente, prometeu ajuda, em especial, financeira, todavia esse repasse nunca se tornou realidade, tal como a posição dos britânicos que tiveram a mesma responsabilidade nesses infortúnios. As contribuições dos bibliotecários dos Estados Unidos e Grã-Bretanha excedem em muito a "ajuda" oficial desses dois países o que, em grande medida, demonstra a falta de interesse em fazê-lo, mesmo depois de grande parte da responsabilidade pelos prejuízos serem causadas pela destruição anglo-americana (BÁEZ, 2006).

Essa tem sido, nas palavras do professor McGuire do Instituto Oriental da Universidade de Chicago, uma "lobotomia" para remover a memória mais profunda de toda uma cultura. A invasão anglo-americana serviu, principalmente, ao objetivo de roubar do Iraque a consciência de seu passado, deixando em aberto para os Estados Unidos, um caminho intelectual para a opressão cultural (ENGLISH, 2005). 


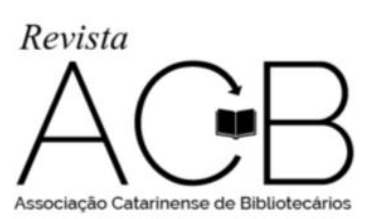

\section{O ASSASSINATO DA INTELECTUALIDADE IRAQUIANA}

A eliminação física de um indivíduo por assassínio é uma forma extrema de terrorismo, que tem efeitos de longo alcance repercutindo por toda a comunidade a que esse indivíduo pertence - neste caso o mundo iraquiano dos intelectuais, acadêmicos, profissionais e líderes criativos nas artes e nas ciências. Por cada intelectual iraquiano assassinado, milhares de iraquianos instruídos fugiram do país ou abandonaram o seu trabalho em troca de uma atividade mais segura e menos vulnerável (PETRAS, 2014).

Durante os doze primeiros meses da guerra e de ocupação haviam morrido cerca de 200 mil civis; para o ano de 2006, os cálculos quase duplicaram ou mesmo triplicaram para essa cifra, enquanto o número de mortes de tropas americanas, em 2005, aproximou dos 2.500 soldados; apenas em outubro de 2005, morreram uma média de 3,5 fuzileiros navais diariamente, excluindo soldados de outros países que também participaram da coalizão, como Itália, Espanha e Reino Unido.

Parte do plano para esvaziar o Iraque de suas coleções culturais, intelectuais e educacionais também tem sido "esvaziar seus cérebros acadêmicos." Desde a queda do regime de Saddam Hussein, a Associação de Professores Universitários denunciou a morte de mais de 100 acadêmicos: a Universidade de Bagdá ocupa o primeiro lugar, seguida pela Universidade de Basra - segunda em importância, a-Mustansiriya, al-Anbar, Mosul e Trikit. Atrás destas, está o Comitê de Educação Técnica, a Universidade Tecnológica de Quedesiya, o Centro de Estudos Superiores e o Centro de Pesquisa contra do Câncer.

As universidades iraquianas, ainda consideradas nas últimas décadas do século passado como as melhores do mundo árabe e que contavam com uma equipe de cerca de 13 mil professores, foram as mais espoliadas dos seus recursos humanos, devido a assassinatos, sequestros e tortura de seus docentes. Mais de mil profissionais emigraram para outros países desde a derrubada de Saddam Hussein (AYAM, 2006).

A destruição sistemática do patrimônio cultural se agregou com a destruição física e moral através da prática de tortura, execuções extrajudiciais, estupros, privação de liberdade para os intelectuais que se recusaram a cooperar com o governo ocupante, praticamente imposto pelos Estados Unidos e seus aliados. Existem outras fontes que acreditam que cerca de mil professores sofreram ameaças contra si a também a suas famílias, bem como foram submetidos a espancamentos e humilhações nos próprios campi universitários. 


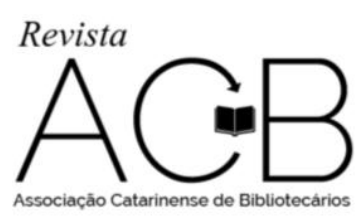

As forças de ocupação juntaram-se ao crescente papel dos líderes religiosos na vida política e cultural do país. Isso resultou na suspensão da liberdade acadêmica e sectarismo nas escolas, o que ocasionou, dentro das universidades, uma série de confrontos entre estudantes, professores e religiosos a fim de impor a corrente xiita. Inclusive, faculdades foram utilizadas para celebrar cerimônias religiosas dentro da linha mais radical do Islã.

Ayam (2006) afirma que novo governo iraquiano tem sido incapaz de controlar esses brutos atos contra professores e pesquisadores, que, acompanhados de outros acadêmicos de países árabes, lutam pela liberdade de expressão e acadêmica em suas universidades. São eles agora que exigem investigação e ensino que correspondam às universidades sem que o governo interfira nestes aspectos.

\section{CONSIDERAÇÕES FINAIS}

Os livros têm, às vezes, o dom de profeticamente abrir-se em páginas reveladoras e dirigir os olhos dos leitores à palavra, linha, parágrafo que mostra a verdade oculta da realidade a nossa volta.

Com relação aos prejuízos causados pelo tsunami, uma manifestação da natureza que tomou o mundo de surpresa, as populações atingidas foram deixadas mais confiantes e contando que esta experiência irá ajudá-los a modificar hábitos e buscar prever que, se no futuro, tiverem o infortúnio de serem afetados por um fenômeno semelhante, estarão melhores preparados para evitar as muitas perdas humanas, materiais e culturais: museus, bibliotecas e outros locais considerados como fonte de conhecimento.

Quanto ao segundo caso, não há dúvida de que o projeto de acabar com a cultura de uma civilização que surgiu no Iraque, responde aos próprios interesses americanos: impor sua visão de ocidente e apropriar-se dos recursos petrolíferos da região, a custa de centenas de milhares de mortos e feridos. O saldo, o completo desaparecimento, incentivado pelo governo americano, de todos os tipos bibliotecas: prédios que abrigavam documentos, museus, centros educacionais, culturais e religiosos: um "memoricídio". Uma guerra que será difícil de esquecer, e ainda mais difícil de quem a provocou, que desde 1991 estava na agenda de numerosas intervenções armadas, que ao longo da história tem perpetrado essa potência mundial, sempre objetivando impor sua forma de vida e seu domínio absoluto. 


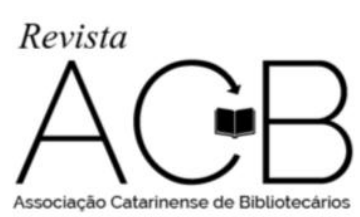

Ante a criação de um tribunal internacional com poderes para julgar crimes contra a humanidade, os Estados Unidos sempre exigiram que seus militares enviados em missões internacionais estejam isentos de sua jurisdição que, eventualmente, Washington sempre se recusa a reconhecer. Porém, é bom que se diga, existem obrigações jurídicas legais internacionais anteriores.

É hora de iniciar uma ação legal para estabelecer as responsabilidades legais e aplicar as sanções correspondentes. Isso não restituirá os livros queimados ou destruídos, mas talvez evite biblioclastias e memoricídios futuros, desestimulando a expectativa de impunidade a seus perpetradores.

\section{REFERENCIAS}

AMARASIRI, Upali. Rising from the wreckage: development of tsunami-affected libraries in Sri Lanka. IFLA Journal, [Edinburg], v. 31, n. 4, p. 307-314, 2005. Disponível em: $<$ http://www.ifla.org/files/assets/hq/publications/ifla-journal/ifla-journal-4-2005.pdf $>$. Acesso em: 12 fev. 2015.

AYAM, Ali. Las universidades iraquíes, al borde de la catástrofe: agresiones confesionales contra la libertad intelectual y el pluralismo en las universidades

Iraquíes. Campaña Estatal contra la Ocupación y por la Soberanía de Iraq (CEOSI), [s. n.], 27 feb. 2006. Disponível em: <http://www.iraqsolidaridad.org/2006/docs/analisis_28-0306.html $>$. Acesso em: 02 jan. 2015.

BÁEZ, Fernando. El enigma de los livros destruídos em Bagdad. Revista Número, Bogotá, v. 21, n. 40, 2003.

História universal da destruição dos livros: das tábuas sumérias à guerra do Iraque. 1. ed. Rio de Janeiro: Ediouro, 2006.

ENGLISH, Sandy. Bibliotecas iraquíes: ¿qué se ha recuperado de um desastre inimaginable?. Campaña Estatal contra la Ocupación y por la Soberanía de Iraq (CEOSI), [s. n.], 17 sep. 2005. (Informe auspiciado por la Asociación de Bibliotecários de Oriente Médio). Disponível em: 〈http://www.iraqsolidaridad.org/2004-2005/docs/econ_22-09-05.html>. Acesso em: 02 jan. 2015.

ESCOLAR SOBRINO, Hipólito. Historia de las Bibliotecas. 3. ed. Madrid: Piramide, 1990. FERREIRA, Aurélio Buarque de Holanda. Dicionário Aurélio da língua portuguesa. 5. ed. Curitiba: Positivo, 2010.

FISK, Robert. Library Books, letters and priceless documents are set ablaze in final chapter of the sacking of Baghdad. The Independent, London, 15 apr. 2003. 


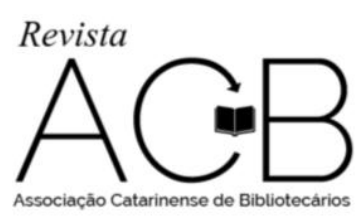

HOUAISS, Antônio; VILLAR, Mauro de Salles. Dicionário Houaiss da língua portuguesa. 1. ed. Rio de Janeiro: Objetiva, 2009.

JAMES, Bonnie. El saqueo de Bagdad: ejemplo del straussiano 'fin de la historia'. Schiller Institute, Washington, [20--]. Disponível em:

<http://www.schillerinstitute.org/newspanish/Noticias/Internacionales/SaqueoBagdag.html >. Acesso em: 27 dez. 2014.

PETRAS, James. A guerra dos EUA contra o Iraque. In: ORIENTE Mídea: culturas da resistência. 2014. Disponível em: <http://www.orientemidia.org/plano-de-eua-nos-vamosfazer-o-iraque-voltar-a-idade-da-pedra/> . Acesso em: 20 fev. 2016.

RAMONET, Ignacio. Tras el tsunami: catástrofe permanente. Comité por la Anulación de la Deuda del Tercer Mundo, Liège, 2005. Disponível em: <http://cadtm.org/Tras-el-tsunamicatastrofe>. Acesso em: 22 mar. 2015.

TRESSERRAS, Jordi Juan. Los efectos del tsunami sobre el patrimonio. La Vanguardia, v. 2, n. 69, 29 abr. 2005. Disponível em: 〈http://www.rebelion.org/noticia.php?id=9921 >. Acesso em: 12 dez. 2014.

TUCÍDIDES. História da guerra do Peloponeso. 3. ed. São Paulo: WMF Martins Fontes, 2013.

YRIART, Martin F. Bagdad, bibliocausto, memoricidio, impunidad. Revista Descontexto, [s.n.], 25 abr. 2008. Disponível em: <http://descontexto.blogspot.com.br/2008/04/bagdadbibliocausto-memoricidio.html >. Acesso em: 27 nov. 2014.

\title{
THE BIBLIOCLASTY IN THE BEGINNING OF THE XXI CENTURY: A TRAGEDY OF TWO FACES
}

\begin{abstract}
As a result of two events which marked the international scenary early in the last decade - a war and a tsunami, this article discusses the situation regarding human loss, physical loss and the damage mainly in several countries in Asia by "Tsunami" and the Iraq war, to the library and the school system. The consequences of these two disasters had a negative impact in the world of culture, either for the delay or the big losses that have meaning in one side, a natural disaster, and on the other side, the terrible scourge of war. The big difference is that the first one was caused by nature itself, and second one, by the hand of men with the intention of making memory loss. Both of them, however, are examples of what the Greeks call "Biblioclasty", i.e. the destruction of libraries.
\end{abstract}

Keywords: Libraries. Biblioclasty. Natural desasters. Destruction of libraries. Memory. 